\title{
Automatic Plant Watering System using Arduino UNO for University Park
}

\author{
Yin Yin Nu1, San San Lwin², Win Win Maw ${ }^{3}$
}

\begin{abstract}
${ }^{1}$ Lecturer, Department of Information Technology, Technological University, Monywa, Myanmar
${ }^{2}$ Lecturer, Department of Information Technology Engineering, Technological University, Kyaukse, Myanmar ${ }^{3}$ Lecturer, Faculty of Computer System and Technologies, University of Computer Studies, Mandalay, Myanmar
\end{abstract}

\begin{abstract}
How to cite this paper: $\mathrm{Yin} \mathrm{Yin} \mathrm{Nu} \mid \mathrm{San}$ San Lwin | Win Win Maw "Automatic Plant Watering System using Arduino UNO for University Park" Published in International Journal of Trend in Scientific Research and Development (ijtsrd), ISSN: 24566470, Volume-3 । Issue-4, June 2019, pp.902-906, URL: https://www.ijtsrd.c om/papers/ijtsrd23 714.pdf

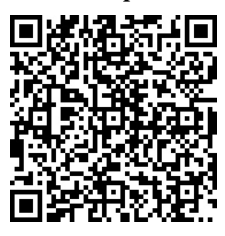

Copyright (C) 2019 by author(s) and International Journal of Trend in Scientific Research and Development Journal. This is an Open Access article distributed under the terms of the Creative Commons

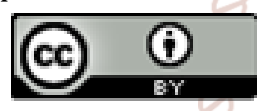
Attribution License (CC BY 4.0) (http://creativecommons.org/licenses/ by/4.0)

\section{INTRODUCTION}

Arduino is an open-source electronics electronic platform based on easy-to-use hardware and software. Arduino boards are able to read inputs- light of sensor, a finger on a button, or a Twitter messages,- and turn it into an outputactivating on a motor, turning on an LED, publishing something online. Over the years Arduino has been the brain of thousands of projects, from everyday objects to complex scientific instruments. A worldwide community of markers has gathered around this open-source platform, their contributions have add to up an incredible amount of accessible knowledge that can be of great help to novices and experts alike.

Arduino was born at the Lvrea Interaction Design Institute as an easy tool for fast prototyping, aimed at students without a background in electronics and programming. As soon as it reached a wider community, the Arduino board started changing to adapt to new needs and challenges, differentiating its offer from simple 8-bit boards to products for IoT application, wearable, 3D printing, and embedded environments. All arduino boards are completely opensource, empowering users to build them independently and eventually adapt them to their particular needs. The software too, is open-source, and it is growing through the contributions of users worldwide.

\section{SYSTEM BLOCK DIAGRAM}

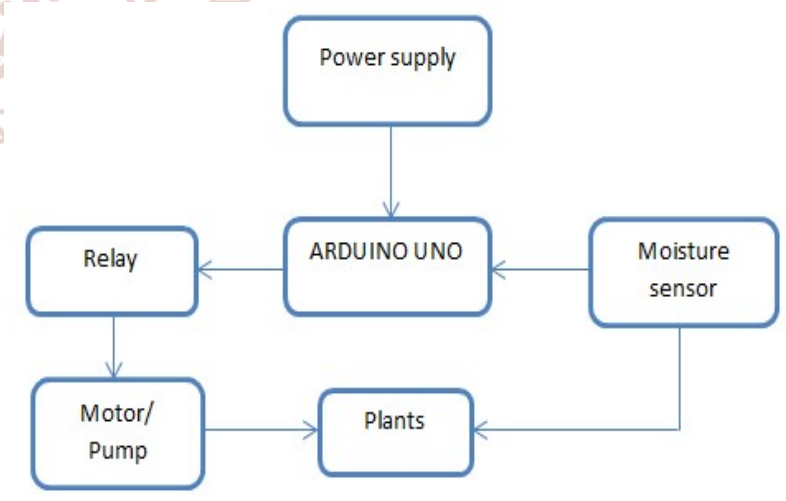

Figure: 1 Block diagram of automatic plant watering system.

There are two functional components in this system. They are the moisture sensors and the motor/water pump. Thus the Arduino Board is programmed using the Arduino IDE software. The function of the moisture sensor is to sense the level of moisture in the soil. The motor/water pump supplies water to the plants.

\section{SYSTEM REQUIREMENTS}

The description of hardware and software components required in the design and implementation are as follow: 
International Journal of Trend in Scientific Research and Development (IJTSRD) @ www.ijtsrd.com eISSN: 2456-6470

Hardware Descriptions

$>$ ATmega 328 microcontroller

$>$ Moisture sensor

$>12 \mathrm{~V}$ DC motor

$>$ Relay module

$>$ Jump wire

$>$ Power supply

Software Description

$>$ Arduino IDE

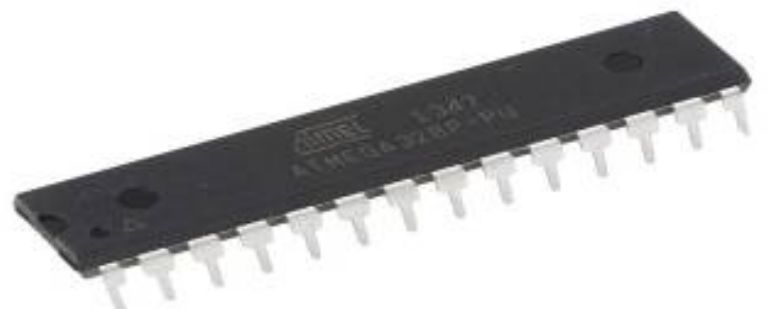

Figure: 2 ATmega 328 microcontroller

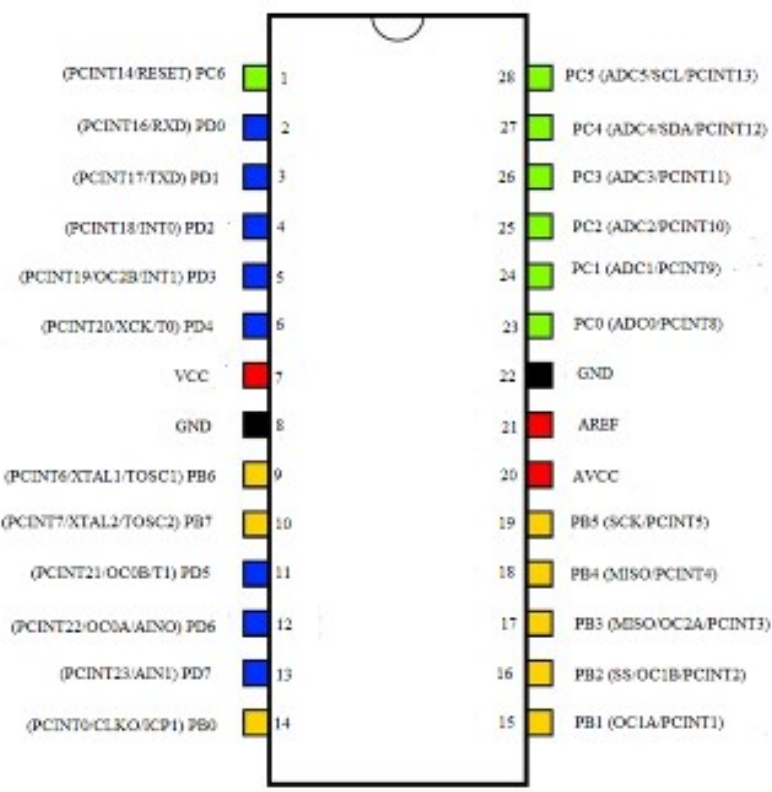

Figure: 3 ATmega 328(AVR) pins

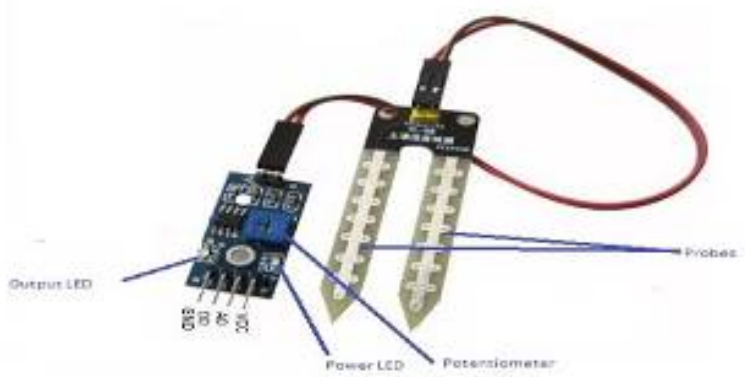

Figure: 4 Moisture sensor

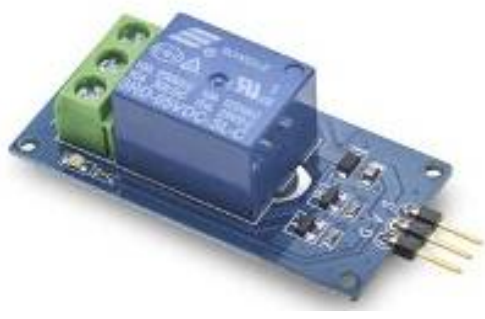

Figure:5 Relay module

5V Relay Terminals and Pins

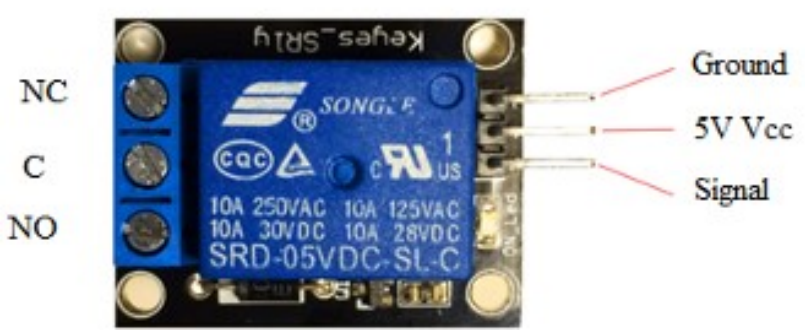

Figure: 6 5V Relay Terminal and Pins

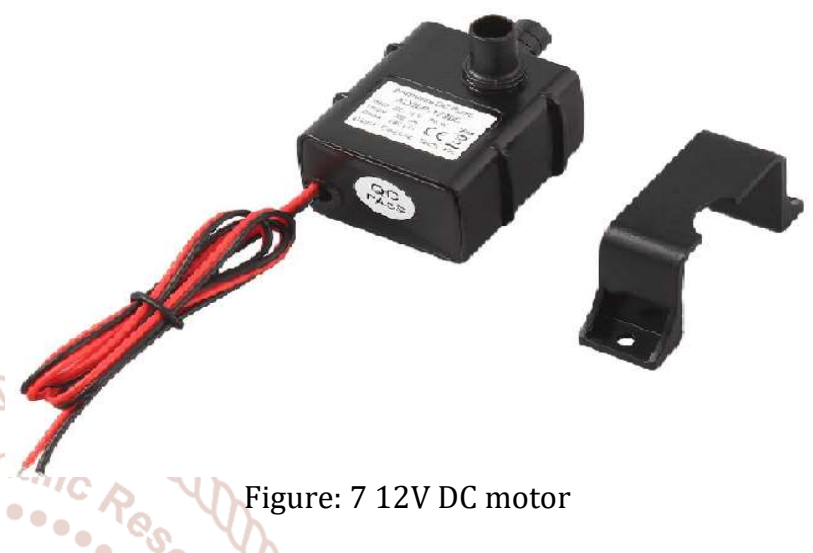

4. SYSTEM WORKING DESIGN

For the purpose of building this system one will need to properly connect following:
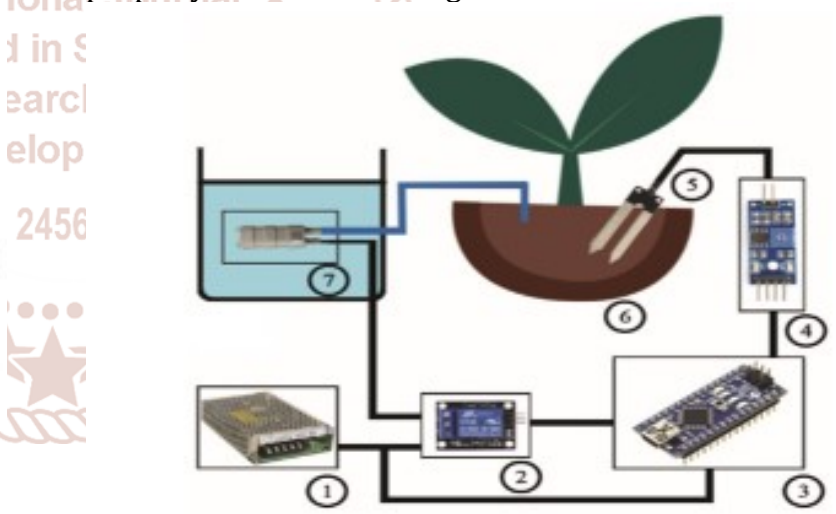

Figure: 8 All materials connected into the system

\subsection{Arduino (UNO) Board}

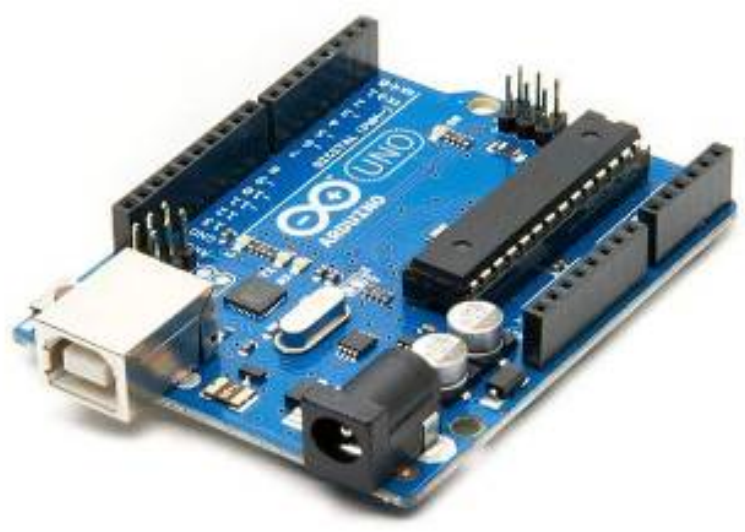

Figure: 9 Arduino UNO Board 
International Journal of Trend in Scientific Research and Development (IJTSRD) @ www.ijtsrd.com eISSN: 2456-6470

This is an Arduino UNO board. Before using it, the program can be compiled from the computer or laptop. After compiling the program, it is ready to use.

\subsection{The process of making system}

Step1: Firstly, Arduino UNO board, relay module, power supply and moisture sensor are setup on the board. These processes are shown in figure;

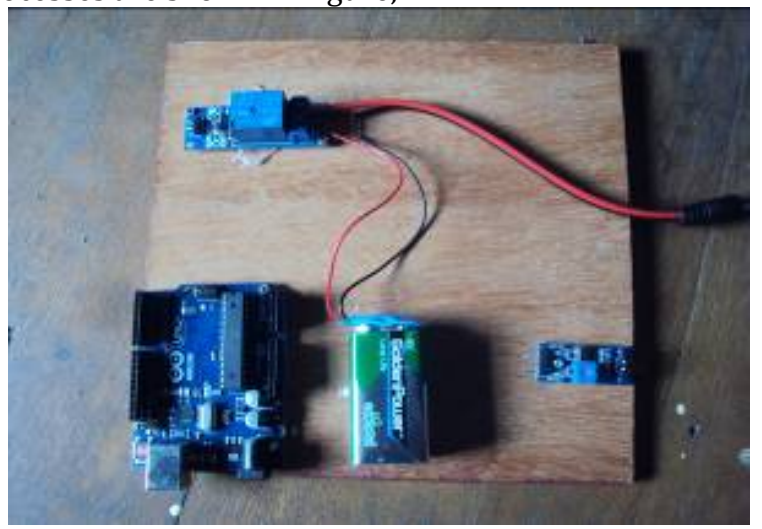

Step2: And then relay and Arduino UNO board are connected in all pins,

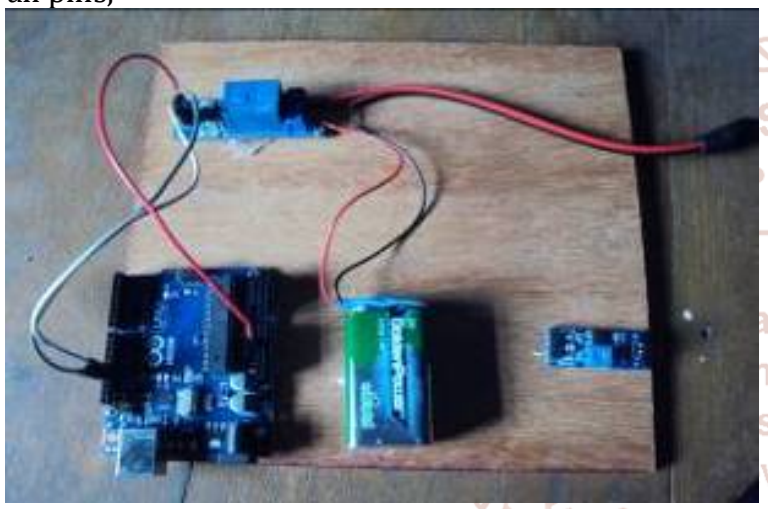

Step3: Moisture sensor is also connected to the UNO board to sense the water content of the plant. This process is shown in figure;

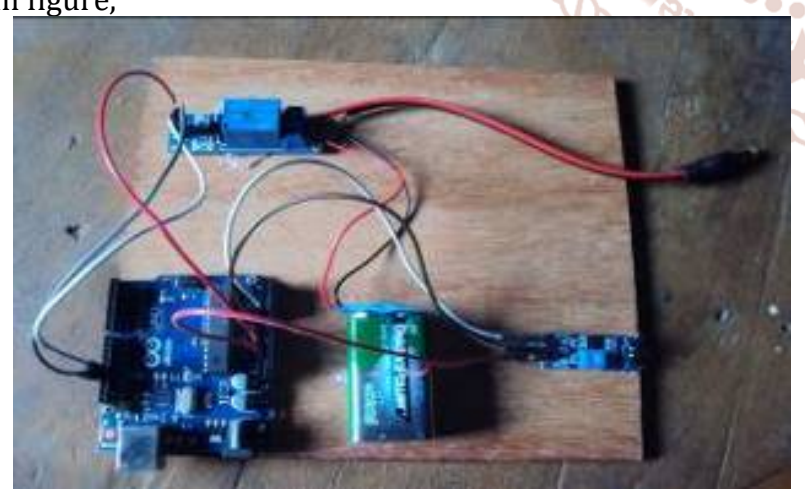

Step4: In this step, the motor is connected to the relay. This is as follows;

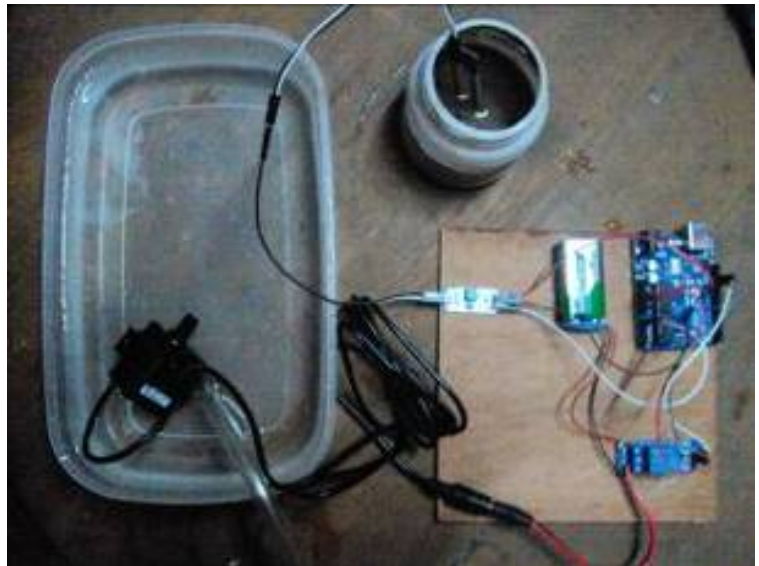

4.3 Pins configuration

Pins configuration of sensor-

Arduino

$3.3 \mathrm{~V}$ pin $\quad=\quad \mathrm{Vcc}$

GND pin $\quad=\quad$ GND

A0 $\quad=\quad \mathrm{A} 0$

Pins configuration of relay module-

Arduino Relay

$5 \mathrm{~V}$ pin $\quad=\quad \mathrm{Vcc}$

GND pin $=\quad$ GND

13 pin $=\quad$ Signal

\subsection{Write the program using Arduino IDE}

The user have had the Arduino IDE software to write the program.

Arduino UNO board is connected to the computer using the USB cable. And then, double-click the Arduino application, and then write the program.

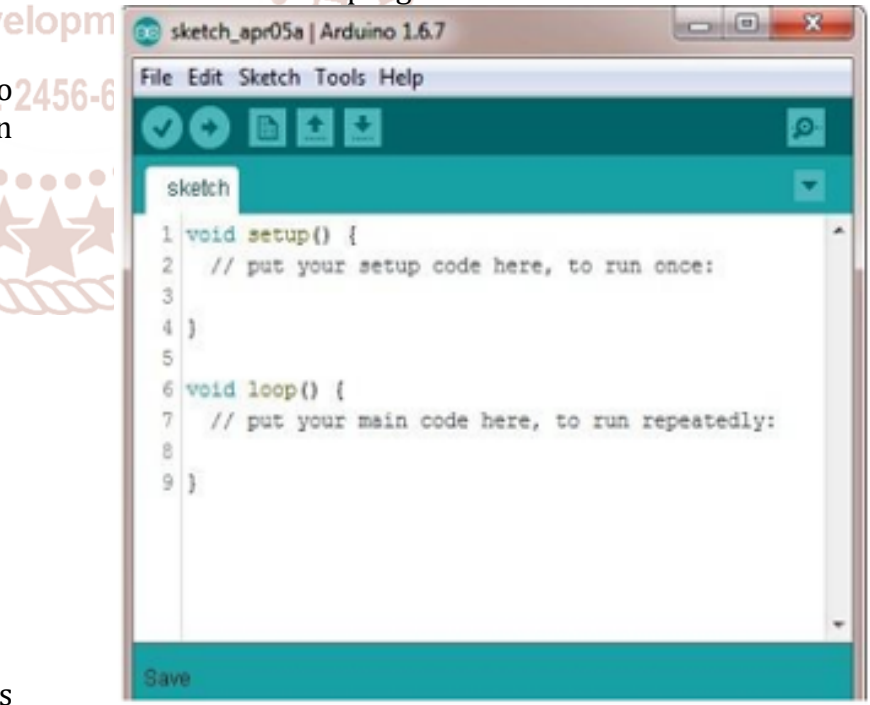

Figure:10 Start creating screen of arduino program

This program uses the functions pinMode (), digitalWrite(), and delay(), which are provided by the internal libraries included in the IDE environment. The user can select the suitable board in the tools bar. 
International Journal of Trend in Scientific Research and Development (IJTSRD) @ www.ijtsrd.com eISSN: 2456-6470

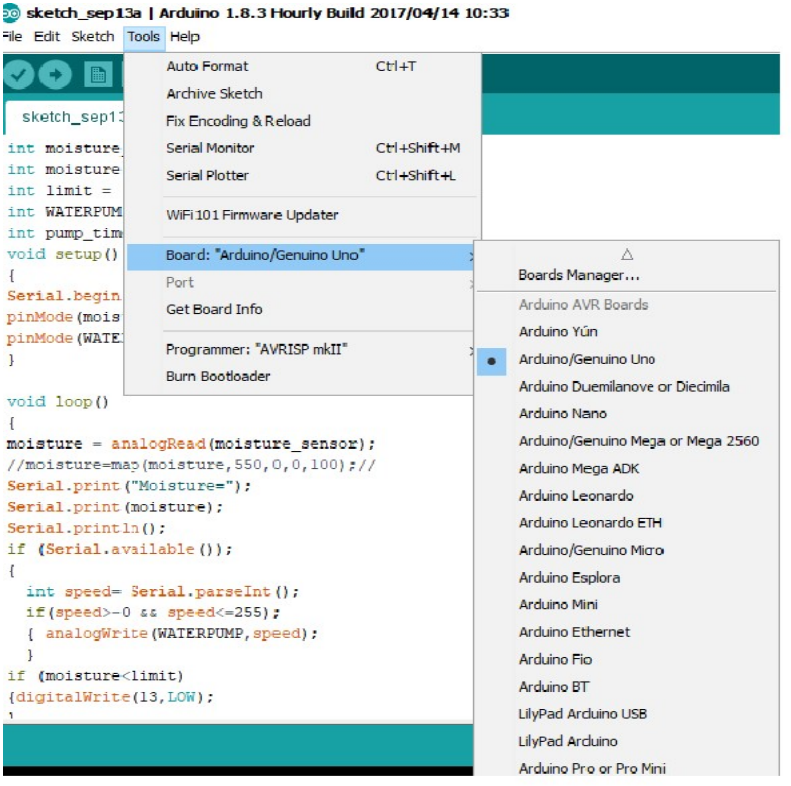

Figure: 11 Select the board

And then, select the serial/COM port that Arduino is attached to:

Tools $>$ Port $>$ COM 3 .

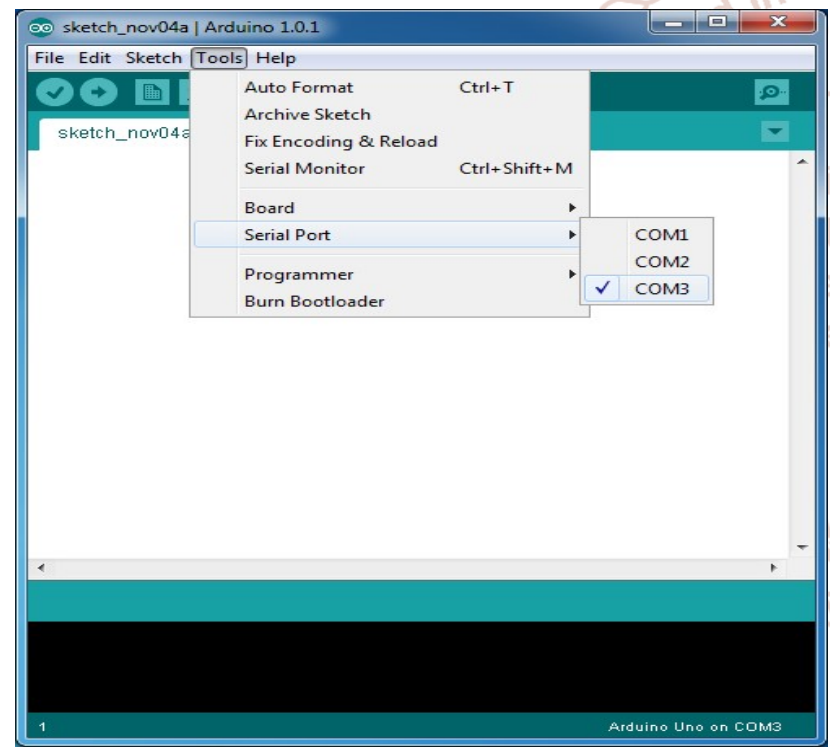

Figure:12 Select the serial port

If the users selected the serial port, the users can write the coding for the process.

Now, simply click the "Upload" button in the environment. Wait a few seconds - the users should see the RX and TX leds on the board flashing. If the upload is successful, the message "Done uploading." will appear in the status bar.

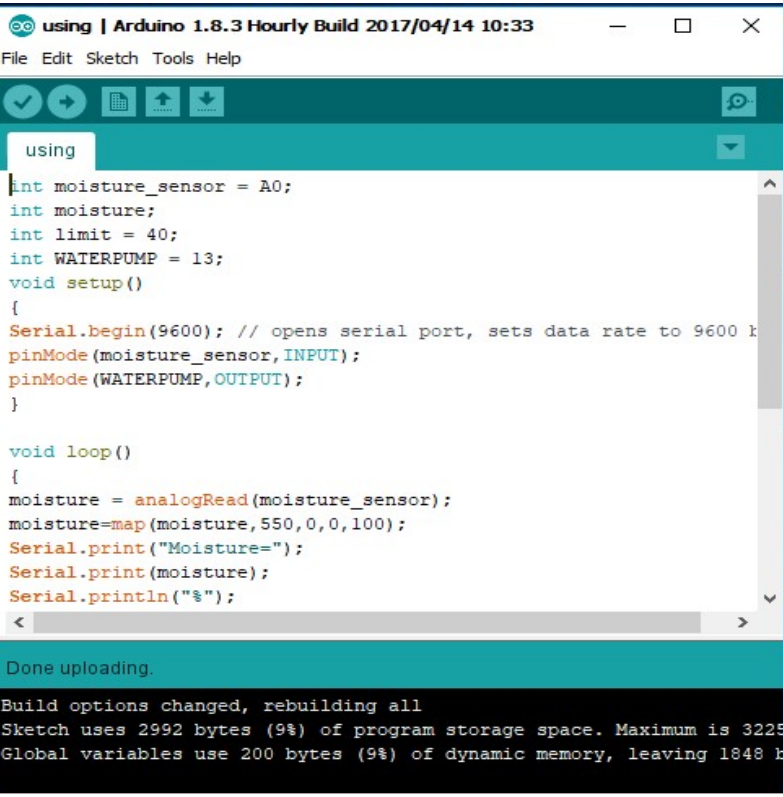

Figure: 13 Upload the program

After uploading the program, the user can see the amount of water content the soil with the serial monitor. The amount of water content is shown by the percentage in figure: 14 . сомз (Arduino/Genuino Uno)

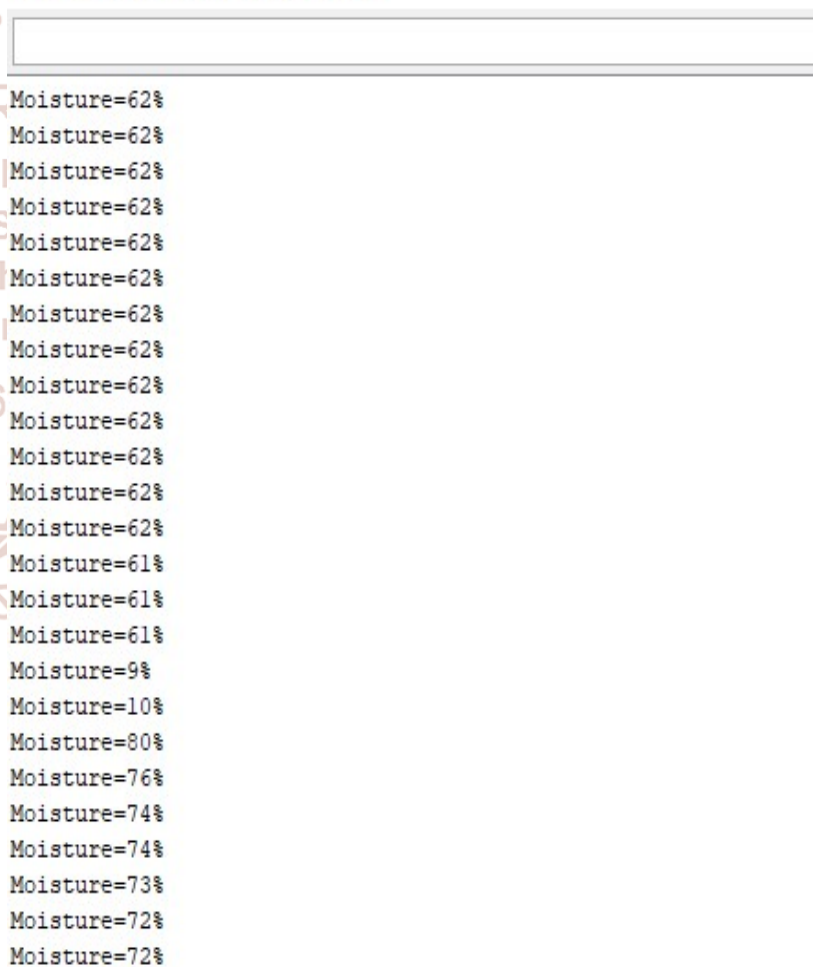

Figure: 14 Monitoring the amount of moisture

\section{CODING FOR THE PROCESS}

int moisture_sensor $=\mathrm{A} 0$;

int moisture;

int limit $=40$;

int WATERPUMP = 13;

void setup()

Serial.begin(9600); // opens serial port, sets data rate to $9600 \mathrm{bps}$ pinMode(moisture_sensor,INPUT); pinMode(WATERPUMP,OUTPUT); 
void $\operatorname{loop}()$

\{

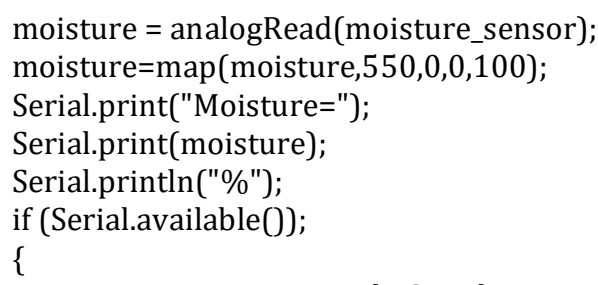

\section{CONCLUSION}

Although it seems to be more demanding and challenging, there are many other possibilities like creating complex connections of plants of similar variety or so-called "Internet of Plants". Also, using more than one sensor is another idea for an experimental venture, but there are also many other experimental and challenge-like ideas such as using solar power supply, timer for setting irrigation system etc. However, independently of the way used to construct it, there is no doubt that this system can be very helpful in solving many problems, from those that seem harmless to those that are on the scale of the most important and most dangerous ones for human population. By means of this system, it is possible to control the amount of water released from the process of watering the plant. This system automation is designed to be assistive for the University Park. Although it can be very helpful for humanity in general, agriculturists, craftsmen, and botanists could have the biggest benefit of using this system.

\section{REFERENCES}

[1] https://components101.com/ microcontrollers/ arduino-uno

[2] http://www.circuitbasics.com/setting-up-a-5v-relayon-the-arduino/

[3] https://vigyanashram.files.wordpress.com/ 2015/05/plant-watering-system.pdf

[4] https://learn.sparkfun.com/tutorials/installingarduino-ide/all.pdf

[5] [14 Dez] Devika et al., International Journal of Advanced Research in Computer Science and Software Engineering 4(10), October - 2014, pp. 449-456

[6] [16 San] Sandeep K. Shukla, IIT Kanpur, Introduction to embedded system, Aug 29, 2016

[7] [16 SHA] SHAIKH SHEROZ MOHD HASAN, 'AUTO IRRIGATION USING ARDUINIO'2016

[8] [17 N.Du] N. Đuzić and D. Đumić: Automatic Plant Watering System and its Applications, Coll.Antropol. 41 (2017) 